\title{
ISOLATED RUPTURES OF THE SUPRASPINATUS MUSCLE
}

\author{
Radomír Holibka*a, Rudolf Ditmara ${ }^{a}$, Alžběta Holibkováb, \\ Stanislav Laichman ${ }^{\text {, }}$ Katherine Růžičkováb \\ a Clinic of Orthopedics, Teaching Hospital, I.P. Pavlova 6, 77520 Olomouc, Czech Republic \\ b Institute of Anatomy, Faculty of Medicine, Palacky University, Hněvotínská 3, 775 15, Olomouc, Czech Republic
}

Received: October 15, 2003; Accepted: October 30, 2003

Key words: Supraspinatus muscle / Arthroscopy / Muscle ruptures / Surgical therapy / Muscle structure

We rarely encounter isolated ruptures of the supraspinatus muscle. At the Clinic of Orthopedics at the Faculty Hospital in Olomouc, we encountered only 21 cases out of 385 arthroscopic operation cases from October 1998 to October 2003. The patients were examined by USG, 5 patients were examined arthrographically and 3 patients underwent MRI examination. Of these 21 patients, only 3 were operated for acute post-injury haemarthrosis of the shoulder joint. During arthroscopic operation, an isolated rupture of the supraspinatus muscle was discovered in all these patients. The remaining 40 patients were only treated at our clinic for problems associated with impingement syndrome after an interval of 3-11 months and were indicated for operational therapy for the rupture of the supraspinatus muscle, verified sonographically and by MRI.

Surgically we performed end to end sutures in 12 patients, in 9 cases we performed refixation using 1-2 titanium MITEK anchors. We supplemented the work by a detailed anatomical study of the supraspinatus muscle on 27 cadaverous anatomical preparations. It was noted that the supraspinatus muscle may be divided into three parts, with a superficial and deep layer of muscle fascicles. An aponeurotic insertion tendon runs through the center, to which part of the superficial muscle fascicles are attached. The muscle fascicles, including the central attachment tendon, run across the superior margin of the shoulder joint and by broad tendon are attached to the superior surface of the greater tubercle of the humerus. Together with the long head of the biceps muscle, they act as a significant shoulder stabiliser. The authors believe that due to the course of the muscle fascicles, this muscle acts as a significant shoulder stabiliser and a powerful abductor and elevator in the shoulder joint. The inferior portion of the muscle fascicles acts as an external rotator of the shoulder.

\section{INTRODUCTION}

The shoulder has the greatest range of motion. The continuity of motion in the shoulder joint is secured not only by the glenohumeral joint, but also by corresponding joints- the acromioclavicular joint, the sternoclavicular joint, and a significant contribution to the range of motion is also ensured by the thoracoscapular and subacromial joints. All of these joints have a very important role in the functioning of the shoulder. Pain and limitations in the range of motion in the shoulder area may have varying causes. With the development of modern diagnostic methods, primarily ultrasound and MRI, but often also arthroscopy, the diagnosis of shoulder disorders may be more precise. A common disorder associated with pain and limitation of motion is impingement syndrome, which may precede or lead to a RC rupture. In our experience, and in that of other orthopedic specialists, impingement syndrome is often diagnosed after a longer-term conservative treatment. Isolated ruptures of the supraspinatus muscle are encountered quite rarely. In this work, we fo- cus on the incidence of isolated ruptures of the supraspinatus muscle, observed at the Clinic of Orthopedics in Olomouc. We contemplate the anatomical structure of this subacromial muscle, whose massive insertion tendon probably prevents ruptures more often than we would expect. With this work, we would like to contribute to the extensive experience and knowledge published in Czech literature and abroad.

\section{MATERIALS AND METHODS}

The total number of studied patients from October 1998 to October 2003 was 385 . From this number, we discovered an isolated rupture in the supraspinatus muscle in only 21 cases (Graph 1). From this number, 14 were males and 7 were females (Graph 2). The average age of the patients was 44 years (Table 1). The patients underwent a thorough clinical examination. In their personal history, 20 patients reported a fall onto their upper limbs, 1 reported a sharp pull to their upper limb (Graph 3). 


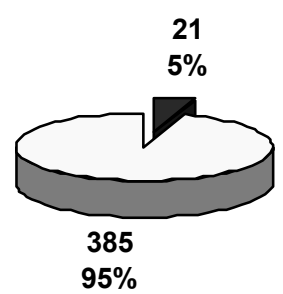

Is olated ruptures $\square$ Others

Graph 1. Isolated ruptures of the supraspinatus muscle

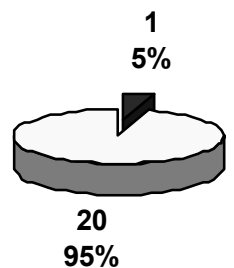

Sharp pull on the $\lim b \quad$ Fall on upper $\lim b$

Graph 3. Causes of isolated rupture

From these 21 patients, 3 were operated for acute post-injury haemarthrosis of the shoulder joint. During arthroscopic operation, the isolated rupture of the supraspinatus muscle was identified and treated. The remaining 18 patients were treated only for shoulder difficulties after diagnosis of impingement syndrome at the clinic and other orthopedic workplaces (Graph 4). All patients were examined ultrasonographically, where the rupture of the supraspinatus muscle was not confirmed in 4 patients (Graph 5). In the course of 3-11 months, after sonographic examination and MRI, they were indicated for operational therapy. In these 7 controversial patients, we performed arthrography. In 6 cases, a rupture was confirmed and in 1 case the examination was negative (Graph 6). In this 1 patient and in additional 2 controversial patients, we performed MRI, which clearly confirmed an isolated rupture of the supraspinatus muscle (Graph 7).

We performed an anatomical study on 27 cadaverous preparations of the upper limb.

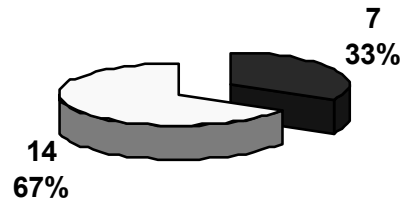

$\square$ Number of women $\square$ Number of men

Graph 2. Isolated ruptures women/men

Table 1. Isolated ruptures - age of patients

\begin{tabular}{|c|c|c|}
\hline \multicolumn{3}{|c|}{ Age of patients (in years) } \\
\hline Average & Minimum & Maximum \\
\hline 44 & 25 & 64 \\
\hline
\end{tabular}

\section{RESULTS}

All patients were operated arthroscopically. After arthroscopical operations, patients are practically without pain, hypotrophy of the deltoid muscle does not occur and rehabilitation is significantly simpler. In 9 cases we performed an "end to end" suture after vitalised blood return to the rupture borders. In 12 patients we performed a refixation of the tendon of the supraspinatus muscle after blood return to the muscle bed on the interface of the border of the humeral head and the greater tubercle with the help of 1-2 titanium anchors (Graph 8). Instrumentarium for arthroscopic sutures were used from the firm MITEK, for both the "end to end" sutures as well as for transosseal refixation with the help of "RC anchors". Post-operationally, a Dessault bandage was applied for 6 weeks. After its removal, only passive rehabilitation was performed for a period of 3 weeks for the purpose of exercising full range of motion. From the $9^{\text {th }}$ week following the operation, all patients were without difficulties, we noted full range of motion and zero pain. After 24 months of follow-up, we removed 20 patients from evidence and considered them cured. After 2 years, 1 patient suffered an extensive traumatic reccurence, who was later operated by open-procedure. During the operation, extensive damage to the rotator cuff was confirmed (Graph 9). 


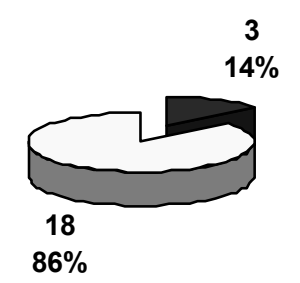

Acute $\square$ After $3-11$ months

Graph 4. Operational solution

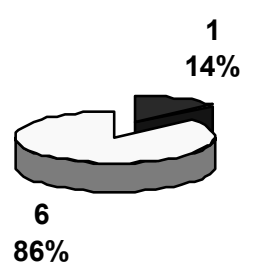

Rupture not confirmed $\square$ Confirmed rupture

Graph 6. Arthrographic examination - 7 patients

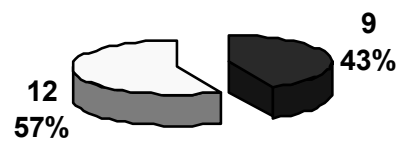

$\square$ End to end $\square$ MITEK - titanium anchors

Graph 8. Surgical solution - Arthroscopy

The muscle is secured in a thick fascial bed. Its tendon in the entry area under the coracoacromial arch is provided with an individual synovial sheath. We discovered that in all the studied muscles, a centrally positioned tendon of aponeurotic appearance runs through the muscle, which passes to the central portion of the extensive attachment tendon and is fixated to the superior surface the greater tubercle of the humerus (Fig. 1, 2). Its insertion is gradual and encompasses a significant part of the greater tubercle of the humerus (Fig. 2). The muscle fascicles can be divided according to their origin and course into several parts (Fig. 3):

1. The most massive muscle fascicles begin on the superior margin of the scapula and from the superior

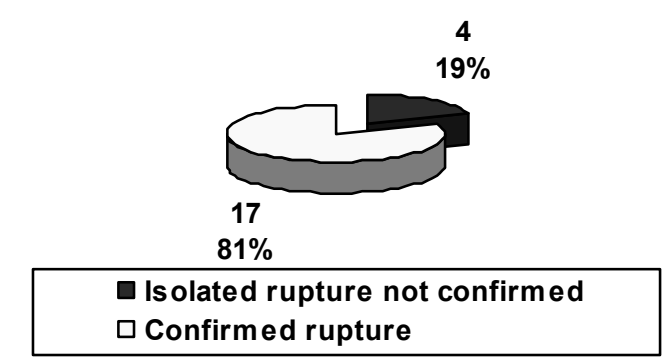

Graph 5. Ultrasound examination - 21 patients

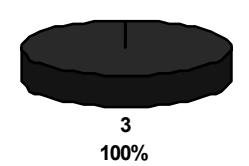

Graph 7. MRI - 3 patients

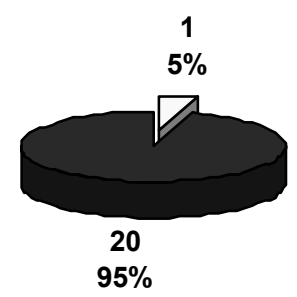

Reoperation (from posttraumatic after 24 months) Without difficulties

Graph 9. Post-operational results after 24 months

angle of the scapula, which partly come into the central aponeurosis laterally. The more massive, superior, deep portion of these fascicles has an opposite course and covers the shoulder capsule, the origin, and the beginning portion of the tendon of the long head of the biceps muscle in full extent.

2. The caudal portion of the fascicles begins on the medial margin of the scapula and moves laterally into the supraspinatus fossa. The beginning medial fascicles have a short craniolateral course and are inserted into the central tendon.

3. The superior muscle fascicles of the infraspinatus muscle are inserted in the attachment tendon (Fig. 4). 
Due to the course of the muscle fascicles and the broad insertion tendon, we believe that the muscle acts as a powerful abductor as well as elevator of the shoulder joint. The deep layer of the superior portion of the muscle probably acts as a quick initial flexor in the glenohumeral joint. The inferior superficial portion, beginning on the medial margin, including associated fascicles of the infraspinatus muscle, act as an external rotator of the shoulder.
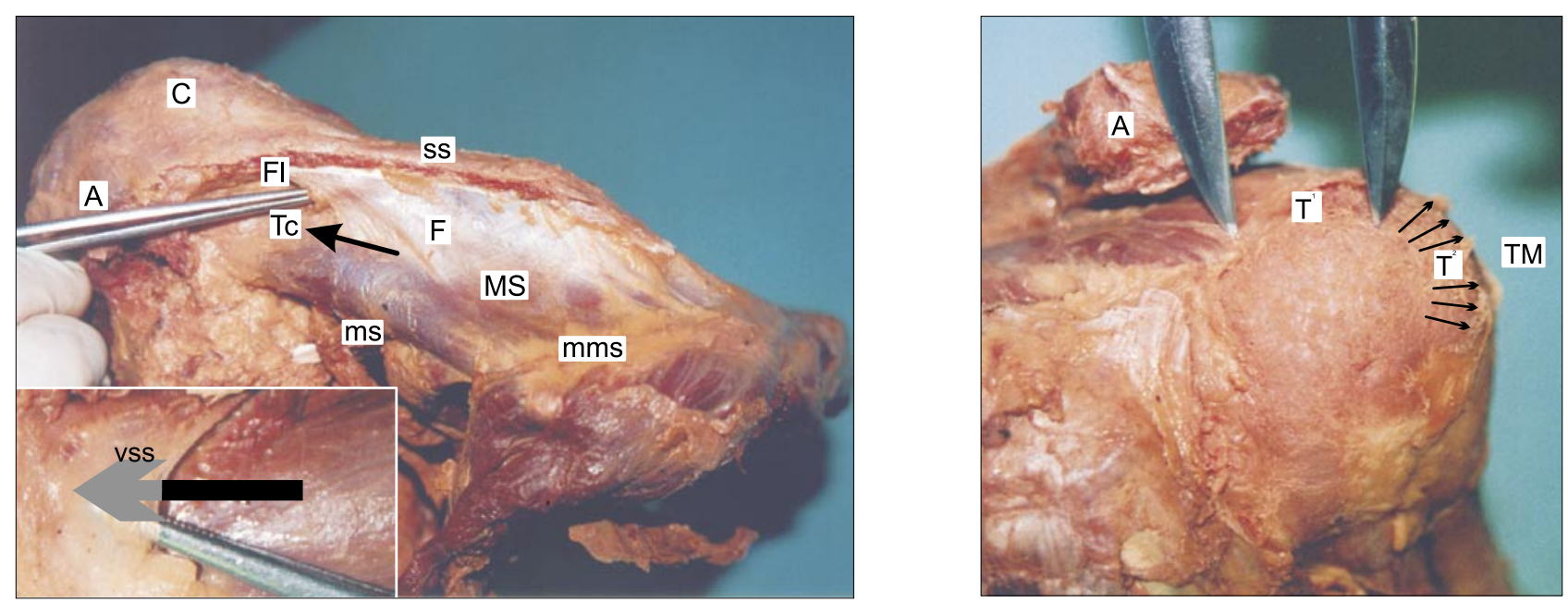

Fig. 1. C - humeral head

A - acromion

Ss - scapular spine

mms - medial margin of the scapula

$\mathrm{ms}$ - superior margin of the scapula

$\mathrm{F}$ - fascia of the supraspinatus muscle

$\mathrm{Fl}$ - muscle bed of the supraspinatus muscle

MS - supraspinatus muscle

Tc - central tendon

vss - synovial sheath of the supraspinatus muscle

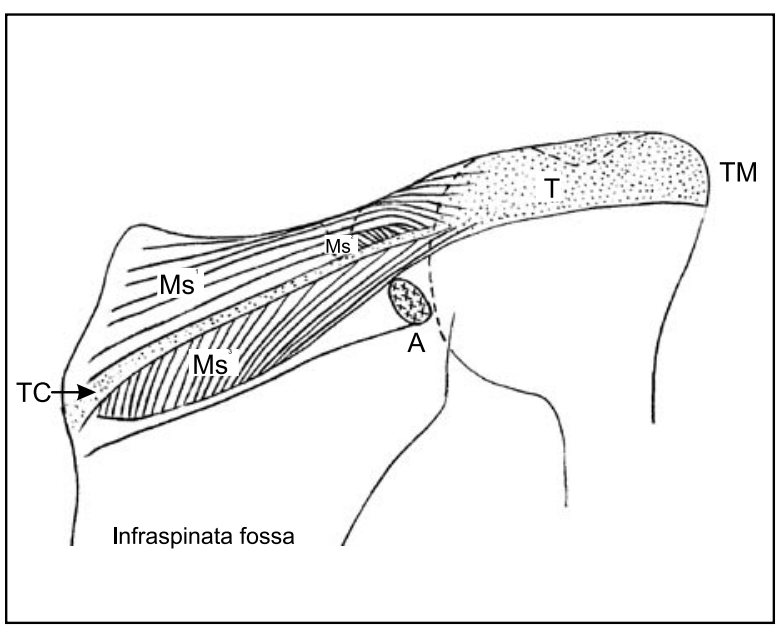

Fig. 3. Scheme:

$\mathrm{Ms}^{1}$ - superficial superior muscle fascicles

$\mathrm{Ms}^{2}$ - deep oblique superior muscle fascicles

$\mathrm{Ms}^{3}$ - inferior muscle fascicles

TC - central tendon

$\mathrm{T}$ - attachment tendon

A - removed acromion

TM - greater tubercle of the humerus
Fig. 2. $T^{1}$ - transition of muscle into attachment tendon $\mathrm{T}^{2}$ - attachment tendon marked with arrows TM - greater tubercle of the humerus A - acromion

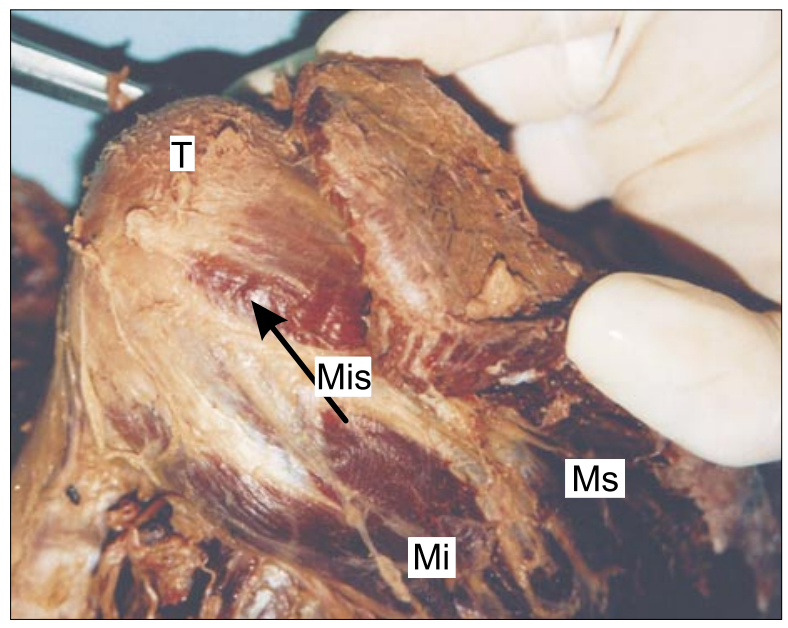

Fig. 4. Ms - supraspinatus muscle $\mathrm{Mi}$ - infraspinatus muscle

$\mathrm{T}$ - attachment tendon of the supraspinatus muscle Mis - attached fascicles of the infraspinatus muscle 


\section{DISCUSSION}

Isolated ruptures of the supraspinatus muscle are very rare. They belong to the classification used at our clinic according to Gschwed I., II. ${ }^{1}$ and III. stages of impingement syndrome. Isolated ruptures of the supraspinatus muscle occur much more frequently than are encountered at the operation table. They are caused by compressions of the subacromial structures-subacromial bursa, synovial sheath of the supraspinatus muscle, loose fibers, which may be caused by repeated inflammation, strenuous work, injury- "supraspinatus outlet"2-4. In athletes-throwers, the injury can appear suddenly $y^{5-7}$. The rupture may also have primary morphological conditions ${ }^{8-10}$. Patients come with shoulder joint pain and limited range of motion ${ }^{11,12}$. We perform the anamnesic collection of data and the basic examination very carefully. We do not evaluate according to the Constant scale ${ }^{13}$, but we evaluate according to the UCLA Score (University of California at Los Angeles shoulder rating scale) which evaluates pain, function, motion, strength and satisfaction of the patient. We evaluate active and passive motion, impingement syndrome tests, Neer test, infiltration impingement tests. We perform tests on the RC muscles and on the long head of the biceps muscle. We perform an x-ray examination as well as a USG examination. Contrary to other authors ${ }^{14,15}$, who obtained excellent results (90-92\%), we obtained only about a $76 \%$ success rate in the results of USG examination of isolated ruptures. That is why in the remaining $24 \%$ of patients, arthrographic examination was performed. The most reliable results were obtained by MRI examination, however, it is not routinely used due to its high financial cost.

Operational solution was performed arthroscopically, which ensured a very good post-operational condition, significantly better rehabilitation, and no hypotrophy of the deltoid muscle ${ }^{16-18}$. The operation is very demanding and requires a skilled surgeon ${ }^{19-21}$.

Together with other authors we concluded that the supraspinatus muscle and its tendon, including its insertion area, have a very good blood supply ${ }^{8,22,23}$. Rupture of this muscle, in our opinion, occurs due to sudden traumatic damage or, more often, during muscle ischemia in impingement syndrome. During these changes, most often the tendon tears $1.5 \mathrm{~cm}$ from the attachment of the "locus minoris resistenciae". The majority of the muscle covers the origin of the long head of the biceps muscle and the glenoid labrum, therefore damage to the muscle is often accompanied by more extensive ruptures ${ }^{1}$, damage to the labrum, SLAP lesions ${ }^{21}$ and glenohumeral ligament damage.

\section{CONCLUSIONS}

1. At the Clinic of Orthopedics at the Teaching Hospital in Olomouc, 385 patients with RC damage underwent arthroscopic operation within 1998-2003. An isolated rupture of the supraspinatus muscle was discovered in only 21 patients.

2. Patients were standardly examined. It was noted, that in isolated ruptures of the supraspinatus muscle, the results of USG diagnosis are worse than with extensive $\mathrm{RC}$ ruptures. All patients with an isolated rupture were treated arthroscopically, 3 of them acutely for post-injury haemarthrosis of the shoulder joint. The others were operated in the course of 3-11 months.

3. The authors performed a detailed anatomical study of the supraspinatus muscle on 27 cadaverous limbs. It has 3 muscle parts. A central tendon passes through the middle, into which a portion of the muscle fascicles is inserted. Due to the course of its muscle fascicles, this muscle occupies a functionally significant position.

4. The authors agree that the tendon of the supraspinatus muscle has a very good blood supply, and that the ruptures are caused by ischemia and tendon damage due to compression of the altered structures under the acromial arch. It is most often $1.5 \mathrm{~cm}$ from its attachment.

5. Operation results after 12 months were excellent. After arthroscopic operation, the pain was minimal to none, no muscle hypotrophy occurred, and the following rehabilitation went very well.

\section{REFERENCES}

1. Gschwend N, Bloch HR, Bischof A. (1991) Langzeitergebnisse der operierten Rotatorenmanschettenruptur. Orthopädie 20, 255-261.

2. Podškubka A. (1999) Impingement syndrom a bolesti ramenního kloubu u sportovců. Acta Chir orthop Traum čech 66, 105-118.

3. Neer CS II. Poppen NK. (1987) Supraspinatus Outlet Orthop Trans $11,234$.

4. Neer CS Il. (1983) Impingement Lesions. Clin Orthop 173, 70-71.

5. Burkhart SS, Morgan CD, Kibler WB. (2000) Shoulder injuries in overhead athletes the "dead arm" revisited. Clin Sports Med 19, 125-158.

6. Almekindrs LC. (2001) Impingement syndrome. Clin Sports Med 20, 491-504.

7. Roye RP, Grana WA, Yates CK. (1995) Arthroscopic Subacromial Decompression: Two- to Seven- Year Follow-up. Arthroscopy 11, 301-306.

8. Bartoníček J, Doskočil M, Heřt J, Sosna A. (1991) Chirurgická anatomie velkých končetinových kloubů. (1 nd ed.). Avicenum, Praha, ISBN 80-201-0151-9.

9. Barthel T, Gohlke F, Gandorfer A, Eulert J. (1995) Die Akromionmorphologie und ihre Darstellbarkeit in der Supraspinatustunnelaufnahme. Arthroskopie 5, 218-223.

10. Codman EA. (1994) The Shoulder, Rupture of the Supraspinatus Tendon and Other Lesions in or About the Subacromial Bursa (1nd ed.) Thomas Todd Co., Boston.

11. Murrell GA, Walton JR. (2001) Diagnosis of rotator cuff tears. Lancet 357, 769-770.

12. Pokorný D, Sosna A, Jahoda D, Pech J, Šimková M, Szekeresová M. (2000) Rehabilitace ramenního kloubu po aloplastice. Acta Chir orthop Traum čech 67, 280-290.

13. Constant RC, Murley AHG. (1987) A Clinical Method for Functional Assessment of the Shoulder. Clin Orthop 214, 160-164.

14. Vaněček I, Kašpárek R. (2000) Ultrasonografické vyšetření rotátorové manžety ramenního kloubu - naše osmileté zkušenosti. Acta Chir orthop Traum čech 67, 316-323. 
15. Bajdová I. (1999) Ultrasonografie rotátorové manžety ramenního kloubu - vyšetření, normální a patologické nálezy. Acta Chir orthop Traum čech 66, 217-224.

16. Gartsman GM. (2001) Arthroscopic rotator cuff repair. Clin orthopaed Research 390, 95-106.

17. Yamaguchi K, Ball CM, Galatz LM. (2001) Arthroscopoic rotartor cuff repair: transition from minoi-open to all-arthroscopic. Clin Orthop 390, 83-94.

18. Yamaguchi K. (2001) Mini-open rotator cuff repair: an updated perspective. Instructional course lectures 50, 53-61.

19. Čihák R. (1978) Anatomie I. (1nd ed.) Avicenum, Zdravotnické nakladatelství, Praha.
20. Holibková A, Laichman S, Holibka R, Zacpalová Z. (2002) The influence of supply on funcion and rehabilitation of the shoulder articulation. The Procceedings of Abstracts of the International Scientific Conference Physical education and Sport 2002, Liberec - Euroregion Nisa, 20.

21. Dvořák, V. (1997) Poranění SLAP - superior labrum anterior posterior. Acta Chir Orthop Traum čech 64, 161-165.

22. Podškubka, A., Staša, M., Dvořák, V., Vaculík, J. (2000) Artroskopická subakromiální dekomprese. Acta Chir orthop Traum čech 67, 175-180.

23. Schroder J, van Dijk CN, Wielinga A, Kerkhoffs GM, Marti RK (2001) Open versus arthroscopic treatment of chronic rotator cuff impingement. Arch of orthopaedic and trauma surgery 121, $241-244$. 